\title{
What Technologies Are Doing to Us
}

\section{Taye Birhanu}

Department of Civics and Ethical Studies, Mettu University, Mettu, Ethiopia

\section{Email address:}

tayex2014@gmail.com

\section{To cite this article:}

Taye Birhanu. Reconsidering What Technologies Are Doing to Us. International Journal of Philosophy. Vol. 8, No. 5, 2020 , pp. $94-99$. doi: $10.11648 /$ j.ijsts.20200805.11

Received: August 12, 2020; Accepted: August 24, 2020; Published: September 8, 2020

\begin{abstract}
The paper exposes the non-neutrality of modern technologies in general and communication and information technologies in particular by focusing on the biases and discriminations that are built-in or embedded in the designs and operation systems of technological artefacts of now a days. The central argument of this paper is that modern technologies are shaping and controlling our life on daily basis often unknown to us, though they appear neutral objects at first glance. The current controversial status of Artificial Intelligence (AI) and human thinking is another main theme of the paper in which it is clearly and strongly argued that it is not worth living to delegate the works of our mind to AI or thinking machines, though there is a tendency of co-acting and sharing the most important distinctive feature/character (creative thinking) of human beings among thinking machines and human beings. Here, arises the need for democratizing and transforming the mainstream of design, operation and decision making in the realm of modern technologies, which in turn requires a thorough critical evaluation and philosophical enquiry into the design and operation of modern technological artefacts.
\end{abstract}

Keywords: Design, Technologists, Technological Artefacts, Non-neutrality, Artificial Intelligence (AI)

\section{Introduction}

Now days, we highly rely on and are being influenced, shaped and controlled by technologies. This is mainly due to the hidden bias and discrimination which is inherent in the designs, operations and networking systems of modern technologies. Therefore, it would be utmost important to deal with issues related to these modern technologies, giving due consideration to philosophical enquiry deep in to their designs. In this paper, I argue that modern technologies are not neutral instruments, but rather they were designed in a manner that could enable them to shape and control our life often unknown to us, because most of the time it is taken for granted that modern technologies are out there to serve humanity innocently. I shall emphasize what technologies are doing to us actually as a result of their politicized designs and operation systems. To put this in the words of Philop Brey:

The embedded values approach holds that computer systems and software are not morally neutral and that it is possible to identify tendencies in them to promote or demote particular moral values and norms [14]. It holds, for example, that computer programs can be supportive of privacy, freedom of information, or the property rights or, instead, to go against the realization of these values. Such tendencies in computer systems are called "embedded", "embodied" or "built-in" moral values or norms. They are built-in in the sense that they can be identified and studied largely or wholly independently of actual uses of the system, although they manifest themselves in a variety of uses of the system [3].

I believe that there is a knowledge gap between our ordinary conception of how and what we do with technologies and what these technologies are doing to us in reality. Hence, in an attempt to bridge this knowledge gap I would pose and attempt some philosophical questions such as: Are we using technology or is it technology that is using us? Are there alternative ways to transform and democratize designs and operations of technologies? Is it desirable to delegate the works of our mind to Artificial Intelligence (AI)? Should we replace our loved ones with our mobile phones!

The second section of my paper, which comes next to this introductory part, presents some of the commonly accepted definitions of technology. Most introductory books of 
philosophy of technology suggest three broad categories of definitions of technology. The first one focuses on characterizing technology as an "applied science". The second category e mphasizes the notion that considers technology as mere hardware tools or instruments [9]. The third category portrays technology as a system of integrated parts of scientific knowledge (theories), organisms and some sort of co-acting (with humans) characters. For the purpose of this paper, I emphasize the third category of definition which characterizes technology as a system. In the third section, I shall discuss the issue of an implicit or hidden nonneutrality of technologies in relation to the designs, networking systems and actual operations of information and communication technologies. The fourth section is devoted to the discussion of issues related to Artificial Intelligence (AI) and human thinking. The fifth section covers the need to democratize technologies deep in their designs and operations or the importance of transforming the politics inside modern technologies by focusing on Andrew Feenberg's thesis of democratizing and transforming technologies as reflected in his book Transforming Technology: A Critical Theory Revisited which was published in 2002. The last section presents concluding remarks.

\section{Technology Defined}

Various philosophers of technology have defined the term technology differently in relation to their respective angles from which they deal with it. Consequently, trying to define technology precisely becomes absurd. Thus, for the purpose of this paper I would present and elaborate some of the commonly accepted definitions of technology that are relevant to the issue under discussion. One such definition of technology is that of Gendron which defines technology as "any systematized practical knowledge, based on experimentation and/or scientific theory, which enhances the capacity of society to produce goods and services, and which is embodied in productive skills, organization and machinery" [4]. This could be taken as a more comprehensive definition of technology because it describes technology as a system by focusing on its organizational aspect as well as in relation to its nature of being part of a body of knowledge or scientific theories. We can also consider a definition by Pacey in which he considers technology as a system in contrary to those definitions that portray technology as a mere tool indicating that "the application of scientific or other knowledge to practical tasks by ordered systems that involve people and organizations, living things, and machines" [4]. It is safe to consider this characterization as a working definition of technology, because it avoids the two extremes where technology is meant to be a mere tool on the one extreme, and identified as if it is solely an "applied science" on the other extreme. Taking in to account these definitions that portray technologies as a system would help us to reconsider whether technologies are neutral in their very design which is the central theme of my paper. One can also consider Mesthene's characterization of technology quoted by Joseph C. Pitt as "the organization of knowledge for the achievement of practical purposes" [13]. He emphasizes the scientific and systemic nature of technologies that strives as a whole (not parts) to realize some desired objectives. Another notion of technology depicted by Heidegger is worth mentioning here. He summarized it as follows:

In enframing, the unconcealment priopriates in conformity with which the work of modern technology reveals the actual as standing-reserve. This work is therefore neither only a human activity nor a mere means within such an activity. The merely instrumental, merely anthropological definition of technology is therefore in principle untenable [13].

From these commonly accepted definitions of technology, it is possible to conclude that technology is a systematized or well organized body of scientific knowledge that could be applied to some practical engagements. Having done more or less the act of defining technology, now, let me turn to discussion of the central theme of my paper.

\section{The Hidden Non-neutrality of Technologies}

When we critically look at the design of new technologies in general and information and communication technologies in particular, it is possible to detect that they are not neutral objects. This is to mean that they have got intentionality in their very design so that they could control and shape us ironically. For instance, "if we take the search engine of an internet, it provides us with a list of priorities or options". Most of the time these options are not ours but had their root in the very design and operation of the search engines which we unconsciously accept and utilize as if they are our genuine choices. In other words they suggest us sources or invite us to their own interests. "The search engines also detect our google accounts such as e-mail" which they usually use to send us back information that is related in some way to what we have searched for at a time but actually serves the interest of the designers. (Note that the quoted examples are taken from my instructor Dr. Setargew Kenaw's class lecture, 2018: AAU; emphasis mine). Brey relates:

Computer systems design includes all kinds of technical limitations and assumptions that are perhaps not value-laden in themselves but that could result in value laden designs, for example because limited screen sizes cannot display all results of a search process, thereby privileging those results that are displayed first, or because computer algorithms or models contain formalized, simplified representations of reality, that introduce biases or limit the autonomy of users, or because software engineering techniques do not allow for adequate security, leading to systematic breaches of privacy [3].

We were forced to rely on information from one side as a result of digital divide particularly from the western world. For example, the Israelis are well known for their innovation 
of new technologies which has been inevitably used to serve their national interests particularly with regard to spying for security issues through inserting spywares in to the software of technological artefacts. Existing literature on the areas of modern technologies in general and technological artefacts in particular clearly shows that we should look at the technological inventions and discoveries as relative to different eras or sensitive to the time and existing reality of the context and period of invention [15]. In other words, the more technologies become sophisticated; the more they discriminate among ordinary people and elite group (the 'technologists'). The non-neutrality of these new technologies is aptly stated by Feenberg in the preface of his book entitled Transforming Technology: A Critical Theory Revisited (2002) as follows:

Modern technology as we know it is no more neutral than medieval cathedrals or the Great Wall of China; it embodies the values of a particular industrial civilization and especially those of elites that rest their claims to hegemony on technical mastery. We must articulate and judge these values in a cultural critique of technology. By so doing, we can begin to grasp the outlines of another possible industrial civilization based on other values. This project requires a different sort of thinking from the dominant technological rationality, a critical rationality capable of reflecting on the larger context of technology [6].

Therefore, in most cases the designers used to inculcate the desired intentionality in to the objects implicitly that could be detected only through critical evaluation of their designs and the ways that these technologies actually operate. Albert Borgmann has stressed this arguing that "there is a real possibility, however, that natural and cultural information will decline to mere utilities, tools we need but fail to sustain as signs of irreplaceable kinds of excellence"[1]. Here what he calls "natural and cultural information" reminded me of what my instructor Dr. Setargew used to say in his class lecture regarding a heavy reliance on a readymade information that these technological artefacts affords us at ease, which results in "outsourcing of our mind indeed". Andrew Feenberg states that "technology is not a fate one must choose for or against, but a challenge to political and social creativity" [5]. To put it another way, the easy availability of information, (particularly as a result of internet revolution) encouraged us to become mere consumer of the existing patterns of thinking/world views coming from every corner, instead of producing contextualized ones. One may insist that this is not the case only for internet sources, but also the same thing holds true for printed books. My response to this anticipated objection is that technological artefacts like cell phone and Personal Computer (PC) have made the access to information and concepts quite easier as compared to other materials such as printed books. Therefore, what matters here is the context and period of time to which we are referring while critically evaluating technologies. Another important issue that I want to raise here is that we need to understand that the term 'modern technology' operates relative to achievements and innovations across various periods of time. For instance, Plato was the first to discuss design issue and its consequences when it comes to the issue of technologies in the context of his time. Therefore, modern technology for him was not a Personal Computer (PC) or cell phone, but it was the first writing technology which was even not as sophisticated as today's photo copying and printing machines. Here, I have borrowed Feenberg's explanation of the issue in which he incorporated direct quotation from Plato's original work as follows:

One of the first educational technologies was writing, and like every subsequent educational technology, it had its critics. Plato denounced the medium for its inability to recreate the give-and-take of spoken discourse. Writing is analogous to painting; he has Socrates argue in The Phaedrus (a text that, fittingly, depicts an intimate conversation between teacher and student): "The painters' products stand before us as though they were alive, but if you question them, they maintain the most majestic silence. It is the same with written words; they seem to talk to you as though they were intelligent, but if you ask them anything about what they say, from a desire to be instructed, they go on telling you just the same thing forever" [5]. In short, Plato holds that the technology of writing has the power to destroy the dialogic relationship that ought to join teacher and student. Technology in the form of writing is the enemy of the human touch, a position familiar from critics of modern life today [6].

At first glance it appears that new technologies are neutral, and out there to serve humanity innocently where the reality goes the reverse. This emanates from conventionally held prejudices and common sense discourse regarding modern technologies, which takes for granted that technologies are all for good with no critical evaluation of the politics that is deep rooted in their (the modern technologies) very designs, as well as networking and operating systems. That is why I argue that they were shaping and controlling us in a manner that is unknown to us. One may contend at this point that modern technologies are making life easier than ever. My reply is that this kind of life in which we heavily rely on technological artefacts even to the extent of "outsourcing our mind indeed" is not desirable; rather it must be "an unexamined life which is not worth living". Socrates used this metaphor to refer to a kind of life which is full of dogmas and superstitions; I use this same metaphor to characterize a kind of life where we rent our mind to technological artefacts. The existing literature in this area clearly confirms this argument beyond doubt, for example, Dusek writes:

After-dinner speeches (our ordinary misconceptions and prejudices) concerning the future of technology traditionally spoke of "man choosing" technologies, as if the choice was unconstrained and mankind as whole rather than powerful interest groups made the choice. The politicians and businesspeople who support or sponsor research lack understanding of the technical aspect (expertise knowledge) of technology. Certainly Ellul is correct that people, whether engineers, businesspeople, or politicians, do not grasp the 
consequences of the technologies that they develop or advocate. While the technologists or the designers having expertise power are generally ignorant and naive about the social and political issues surrounding a technology and the politicians are often abysmally ignorant of the workings of the technology itself, Ellul claims that the public is ignorant of both the technical and the social aspects of the technology. Ellul further claims that the religious leaders (expected to divert the dimension) who are supposed to deal with the value issues of society's use of the technology are ignorant of the technical and social issues, while no one listens to the philosophers who evaluate technologies [4].

As it could be grasped from the above quotation, the general public as well as those public figures who are particularly concerned with the role of leadership in different aspects of life of the society were not well-informed the issue of designs of technological artefacts and its consequences, though they were expected to divert the dimension. Those who fund/sponsor projects and researches in the high-risk technologies also lack the necessary awareness concerning what and how it should be done. Viewed from the other side the "technologists" do not possess the necessary knowledge regarding the far reaching consequences of what they are doing in the back yard (unknown to the general public) on the existing social and political realities [7]. As the famous quote of ancient Chinese philosopher Confucius goes "ignorance is the night of mind, but a night without moon and star", it is really sad that with this huge knowledge disparity, that most of the above mentioned stakeholders ("technologists" and policy makers) were not willing to learn from the works or critical assessments of technologies done by prominent philosophers of technology.

Another issue worth mentioning here is digital divide that might discriminate among various portions of a society and sometimes between different societies. This sort of bias is often engrained in the designs and operating systems of modern technologies as the name itself or 'digital divide' hints. [3] emphasized in his work that digital divide might take different forms of biases or discriminations from which I selected only one instance in order to support my claim. Either deliberately or mistakenly digital systems were designed and networked with the character of favouring a portion of a certain society at the expense of the other. $\mathrm{He}$ writes:

Emergent bias arises when the social context in which the system is used is not the one intended by its designers. In the new context, the system may not adequately support the capabilities, values or interests of some user groups or the interests of other stakeholders. For example, an ATM that relies heavily on written instructions may be installed in a neighbourhood with a predominantly illiterate population [3].

\section{Artificial Intelligence (AI) and Human Thinking}

When it comes to the issue of AIs, they were designed to co-act with humans in the areas of mental processes like thinking. That is why we sometimes call them 'thinking machines'. In other words they were invented as an extension of human beings sharing some our characters with us. Recently the status of $\mathrm{AI}$ is claiming to possess the unique feature of human being (thinking creatively) as another equivalent (with humans) agent which Latour calls 'actant'. In the introductory part of my paper, I have indicated one important philosophical question: Is it desirable to delegate the work of our mind to AI? This remains an open question, because the very objective of the designers/ inventors is to realize the empowerment of AI so that they can think, act and react on behalf of human beings. However, the effort to create 'thinking machine' has faced a serious impediment of responding to dynamism in the act of thinking. Albert Borgmann states that hothing so engages the fullness of human capabilities as a coherent and focused world of natural information" [1]. Haraway relates:

Basically machines were not self-moving, self-designing, and autonomous. They could not achieve man's dream, only mock it. They were not man, an author to himself, but only a caricature of that masculinist reproductive dream. To think they were otherwise was paranoid. Now we are not so sure. Late twentieth century machines have made thoroughly ambiguous the difference between natural and artificial, mind and body, self-developing and externally designed, and many other distinctions that used to apply to organisms and machines. Our machines are disturbingly lively, and we ourselves frighteningly inert [8].

Technological artefacts were designed and are being designed as actors having their own characters where the 'scripts' in fact belong to the designers and operators which they inculcate in to the AI in the form of sophisticated software. Therefore, analogously speaking, the designers of modern technologies are the script writers, editors, directors and producers whereas the technological artefacts are well trained professional actors and actresses who play their respective characters as per the principles of the script. As it can be grasped from the above analogy with a film industry, it is inevitable, that the designers or inventors of AI incorporate intentionality that favours their desires and inclinations (both personal and group interests) in to the software. For example, pilotless aircrafts, particularly in the military science operates with a remote control in which both the designers and the operators deliberately enabled the AI (in this case pilotless aircrafts) to either bombard or spy the exact target of their concern. Latour relates:

Instead of thinking in terms of surfaces-two dimension-or spheres-three dimension-one is asked to think in terms of nodes that have as many dimensions as they have connections (to mean very complicated or sophisticated which becomes too difficult for a lay man to grasp). As a first approximation, the Actor-Theory (AT) claims that modern societies cannot be described without recognizing them as having a fibrous, thread-like, wiry, stringy, ropy, capillary character that is never captured by the notions of levels, layers, territories, spheres, categories, structure, systems. It 
aims at explaining the effects accounted for by those traditional words (due to limited or no access to technical terms) without having to buy the ontology, topology and politics that go with them. AT has been developed by students of science and technology and their claim is that it is utterly impossible to understand what holds the society together without reinjecting in its fabric the facts manufactured by natural and social sciences and the artefacts designed by engineers (therefore, deliberate). As a second approximation, AT is thus the claim that the only way to achieve this reinjection of the things into our understanding of the social fabrics is through a network-like ontology and social theory [11].

\section{The Need for Democratizing Technologies}

So far, I have arguably shown that modern technologies in general and communication and information technological artefacts are not neutral objects or instruments, rather they were designed with deliberately adjusted characters, and hence operate in a manner that is often compatible only with the desires, inclinations and goals of the 'technologists'. Therefore, arises, the need for the democratization of technologies deep in their design and operating systems. Here, I use the term 'democratizing' in a different sense from its political context, as the main concern of my paper is not the political implications technologies, but philosophical enquiry in to design issues and its consequences. Accordingly, it ('democratizing') refers to the act of broadening the realm or the horizon of knowledge in the areas of the design procedures of technological artefacts, methods and mechanisms or know-how of operating modern technologies and the extent to which the distinctive feature of human beings or human thinking has to be delegated to AI. This should be done through making all the stakeholders active participants in the procedures ranging from identifying whether the general public is really in a position of being acquainted with the actual and potential modern technologies. Feenberg writes:

A good society should enlarge the personal freedom of its members while enabling them or the beneficiaries of technological artefacts to participate effectively in a widening range of public activities. At the highest level, public life involves choices about what it means to be human. Today these choices are increasingly mediated by technical decisions. What human beings are and will become is decided in the shape of our tools no less than in the action of statesmen and political movements. The design of technology is thus an ontological (non-neutral) decision fraught with political consequences. The (deliberate) exclusion of the vast majority from participation in this decision is profoundly undemocratic [6].

Another crucial issue needs to be considered here is the marginalization of the general public or the beneficiaries from the mainstream of administration and decision making procedures concerning design issues as it was monopolized by the 'technologists' [2]. Often they do this deliberately, through coining technical codes, terms and symbols that are not open to public knowledge, abusing their expertise power indeed. Therefore, in order to 'transform' and 'democratize' modern technologies, it would be mandatory to become wellaware of the hidden agendas of the 'technologists', which in turn requires us to avoid our prejudices or the traditional after-dinner talk of technologies that portrays modern technologies as neutral objects. Feenberg relates:

Often current technical methods or standards were once discursively formulated as values and at some time in the past translated into the technical codes we take for granted today. The political implication of this approach has to do with the ethical limits of modern technical codes. To the extent that the system is based on the operational autonomy of management, it is specifically armored against the recognition of many participant interests. That armoring shows up in technical designs that deskill, injure, pollute, and otherwise harm those excluded from a share in technical power. The very same process in which capitalists and technocrats were freed to make technical decisions without regard for the needs of workers and communities generated a wealth of new "values," ethical demands forced to seek voice discursively and realization in the new technical arrangements. Most fundamentally, democratization of technology is about privileging these excluded values and the publics that articulate them [6].

\section{Conclusion}

Modern technologies in general and communication and information technologies in particular are not neutral (not free from bias and discrimination which is inherent in their very designs, operations and networking systems), though they appear as if they are neutral objects at first glance. This paper has been trying to confirm that technological artefacts have got intentionality that is built-in them at their very design stage in a manner that is compatible with the prime interest of the designers which enabled the technological artefacts to operate in favour of the 'technologists' (designers) often unknown to the ordinary people or the beneficiaries.

The hidden non-neutrality of modern technological artefacts cannot be detected with our common sense presumptions, prejudices and traditional after-dinner talk about technologies, rather it requires a thorough critical assessment and philosophical enquiries deep in to the design strategies of the modern technologies as well as its consequences. This can be done through considering technology as a system of integrated scientific theories, strategies, organisms and machines that co-act so as to secure certain practical purposes. That is why I suggested avoidance of the two extremes in an attempt to characterize or define technology: the one in which technology is reduced to mere hard ware tools and another one where it (technology) is portrayed solely as an "applied science". Therefore, dealing 
with design issue of modern technologies and its consequences involves critical evaluation of politics inside technologies (bias and discrimination deep rooted in their designs and operations), which this paper has been trying to establish arguably.

AI and human thinking have shown the tendency or inclination to co-act and reinforce one another these days, though whether that has to be the case remains a philosophical puzzle. I argue that it is not worth living to delegate the work of our mind to thinking machines because it is inevitable that the AI operates or functions as per the instructions of the designers and inventors which I have illustrated in this paper analogously, attributing the role of playing characters to the AI (as actors and actresses in the film industry) and the designers and inventors of AI as script writers, directors, editors and producers of the film [10]. Therefore, we should rethink and reconsider where we are going with this mentality of considering AI as an extension of human beings; sharing some of our distinctive characters/features, most importantly creative thinking, which I doubt may over power us at the end of the day with no exception for its (AI) inventors (creators) [12].

Having understood that modern technologies are being designed and operating in favour of the 'technologists', there should be a demand for an alternative remedy. Consequently, I have suggested and argued for the thesis of 'democratizing and transforming technologies' developed by Andrew Feenberg. Therefore, the horizon or the realm of knowledge, pertaining to modern technologies particularly regarding technical mastery of the technological artefacts should be broadened, being open for both the 'technologists' and the general public (beneficiaries). More importantly decision making procedures such as devising strategies for designs of the technological artefacts, the need for availability of more potential technologies and the limits on the extent to which AI can share human characters should allow all the stakeholders to become active participants.

\section{Acknowledgements}

First and foremost, I would like to thank and appreciate Dr. Setargew Kenaw for tirelessly providing me with constructive comments that added value to the earlier versions of the paper. Next, I would like to owe my indebted gratitude to my colleagues for raising important questions, offering me reliable suggestions and comments during our informal discussions as well as while I was presenting my paper to the staff which enabled me to enrich the paper, especially to Biniam Fanta, who came up with a wellorganized peer review of the paper.

\section{References}

[1] Borgmann, A. (1999) Holding on to Reality: The Nature of Information at the Turn of the Millennium. Chicago: University of Chicago Press.

[2] Bostrom, N., and Milan M. Ć., eds. (2008) Global Catastrophic Risks. NewYork: Oxford University Press.

[3] Brey, P. (2009). 'Values in Technology and Disclosive Computer Ethics', The Cambridge Handbook of Information and Computer Ethics, Ed. L. Floridi, Cambridge: Cambridge University Press.

[4] Dusek, V. (2006) Philosophy of Technology: An Introduction. London: Blackwell.

[5] Feenberg, A. (1999) Questioning Technology. London: Routledge.

[6] Feenberg, A. (2002) Transforming Technology: A Critical Theory Revisited. New York: Oxford University Press

[7] Good, Irving J. (1965) "Speculations Concerning the First Ultra intelligent Machine." In Advances in Computers, edited by Franz L. Alt and Morris Rubinoff, 3188. Vol.6. New York: Academic Press. doi: 10.1016/S0065-2458(08)604180.

[8] Haraway, D. (1991) "A Cyborg Manifesto: Science, Technology, and Socialist-Feminism in the Late Twentieth Century", in Simians, Cyborgs and Women: The Reinvention of Nature. New York: Routledge, pp. 149-181.

[9] Howard, P. (1994) The Death of Common Sense: How Law is Suffocating America. New York: Random House.

[10] Kurzweil, R. (2005) The Singularity Is Near: When Humans Transcend Biology. New York: Viking.

[11] Latour, B. (1990) 'On Actor-Network Theory. A few Clarifications plus more than a few A few complications' in Soziale Welt, Vol. 47, pp. 369-381, 1996.

[12] Omohundro, Stephen M. 2008. “The Basic AI Drives.” In Artificial General Intelligence 2008: Proceedings of the First AGI Conference, edited by Pei Wang, Ben Goertzel, and Stan Franklin, 483492. Frontiersin Artificial Intelligence and Applications 171. Amsterdam: IOS.

[13] Pitt, J. (2000) Thinking about Technology: Foundations of Philosophy of Technology. New York: Seven Bridges Press.

[14] Warren, Mary. (1997) Moral Status: Obligations to Persons and Other Living Things. Issues in Biomedical Ethics. New York: Oxford University Press. doi: 10.1093/acprof:oso/9780198250401.001. 0001.

[15] Yudkowsky, E. (2008) “Artificial Intelligence as a Positive and Negative Factorin Global Risk. "In Global Catastrophic Risks, edited by Nick Bostromand Milan M. Ćirković, 308345. NewYork: Oxford University Press. 